\title{
Efficacy and tolerability of liposomal polyvinylpyrrolidone-iodine hydrogel for the localized treatment of chronic infective, inflammatory, dermatoses: an uncontrolled pilot study
}

This article was published in the following Dove Press journal:

Clinical, Cosmetic and Investigational Dermatology

22 September 2017

Number of times this article has been viewed

\section{Matthias Augustin' \\ Lisa Goepel ${ }^{2}$ \\ Arnd Jacobi ${ }^{2}$ \\ Bjoern Bosse ${ }^{3}$ \\ Stefan Mueller ${ }^{3}$ \\ Michael Hopp ${ }^{3}$}

'Department of Dermatology, University-Hospital Freiburg, Freiburg, ${ }^{2}$ Institute for Health Services Research in Dermatology and Nursing (IVDP), University Medical Center Hamburg-Eppendorf, University of Hamburg, Hamburg, ${ }^{3}$ Mundipharma Research GmbH \& Co.KG, Limburg (Lahn), Germany
Correspondence: Stefan Mueller Mundipharma Research GmbH \& Co.KG, Höhenstr. 10, 65549 Limburg (Lahn), Germany

Tel +49 643 I 70l 43।

Fax +49 6431 701 843।

Email Stefan.Mueller@mundipharma-rd.eu
Abstract: Infection is common in many chronic, inflammatory skin conditions but is often difficult to treat, in part due to growing bacterial resistance to antibiotics. Liposomal polyvinylpyrrolidone (PVP)-iodine hydrogel has a unique mode of action, combining the antiseptic and anti-inflammatory actions of PVP-iodine with the drug delivery and moisturizing properties of liposomes. We investigated the utility of liposomal PVP-iodine to treat infective dermatoses. In this prospective, single-arm (uncontrolled), open-label Phase II pilot study, patients with acne vulgaris $(n=30)$, atopic dermatitis $(n=20)$, impetigo contagiosa $(n=10)$, and rosacea $(n=10)$ received PVP-iodine (3\%) hydrogel for $\leq 4$ weeks. Global Clinical Severity score improved for all dermatoses (range: 0.5 for acne vulgaris $[p<0.001]$ to 1.0 for impetigo contagiosa $[p=0.011]$ ). Improvements in pain, quality of life, (Freiburg Life Quality Assessment), and Eczema Area and Severity Index scores were also seen. Treatment was well tolerated; most frequent adverse events were burning (14\%) or itching (9\%) sensations. Thus, liposomal PVP-iodine hydrogel has potential utility as an effective treatment for inflammatory skin conditions associated with bacterial colonization

Keywords: acne vulgaris, atopic dermatitis, impetigo contagiosa, liposomal PVP-iodine hydrogel, polyvinylpyrrolidone, rosacea

\section{Introduction}

Chronic skin conditions are among the leading causes of nonfatal disease burden worldwide. ${ }^{1}$ Diseases such as acne vulgaris, atopic dermatitis, impetigo contagiosa, and rosacea negatively impact numerous aspects of patients' quality of life, increasing their risk of depression and anxiety, as well as feelings of social inhibition and low self-esteem. ${ }^{2-6}$

Many chronic skin diseases involve a complex interplay between skin barrier abnormalities, immune dysregulation, and an infectious component. For example, in acne vulgaris, seborrhea and altered keratinocyte differentiation at the hair follicle leads to blockage of sebum secretion and comedones, promoting follicular colonization by Propionibacterium acnes which induces the release of inflammatory mediators. ${ }^{2,7}$ Colonization by Staphylococcus aureus is very common in patients with atopic dermatitis and impetigo contagiosa, with bacterial alpha toxins aggravating these conditions. ${ }^{8-12}$ While the underlying causes of rosacea are less clearly defined, evidence also points 
toward a role of colonization by Staphylococcus epidermis and Bacillus oleronius. ${ }^{13-15}$

The management of infective dermatoses presents numerous challenges which include the sensitive skin of affected individuals and difficulties accessing the site of the underlying infection. Due to their multifactorial etiology, a variety of treatments are used to manage infective dermatoses, including pharmacological and nonpharmacological approaches. $^{16-21}$

Topical antibiotics and antiseptics are commonly used in combination to control mild-to-moderate acne, with oral antibiotics being reserved for patients with more severe symptoms. ${ }^{2,19,22}$ There is a lack of agreement regarding standard therapy to manage the infective component of impetigo contagiosa. ${ }^{11,23,24}$ Despite an infective component in the etiology of atopic dermatitis or rosacea, topical antibiotics are not generally recommended. ${ }^{16-18}$ Patients with infective dermatoses who are treated with antibiotics quickly become recolonized, and the bacteria associated with impetigo, atopic dermatitis, and acne vulgaris are demonstrating growing resistance to commonly used antibiotics. ${ }^{9,12,25-27}$ Furthermore, formation of biofilms can exacerbate symptoms of infective dermatoses and increase bacterial resistance to antibiotics. ${ }^{28-30}$ Consequently, there is a substantial need for efficacious and well-tolerated alternate agents to target bacterial colonization in order to manage infective, inflammatory skin conditions.

Liposomal drug products provide topical activity and are generally considered less toxic than conventional drug formulations. ${ }^{31} \mathrm{~A}$ wide variety of liposomal drugs are currently marketed. ${ }^{32}$ Liposomes are composed of concentric phospholipid bilayers and can enhance the penetration of drugs into skin and mucus membranes. These multilamellar vesicles also act as microreservoirs to prolong the release of active ingredient. ${ }^{31}$ Liposomal polyvinylpyrrolidone (PVP)-iodine (3\%) hydrogel (Repithel ${ }^{\circledR} /$ Repigel $^{\circledR}$, [Mundipharma GmbH, Limburg, Germany] marketed in Germany, Switzerland, and South Korea) combines the antiseptic activity of PVP-iodine with the drug delivery properties and moisturizing effects of liposomes. ${ }^{31}$ PVP-iodine is an established antiseptic and has been used as a skin cleanser in atopic dermatitis and acne vulgaris. ${ }^{33,34}$ PVP-iodine ointment has also been shown to reduce inflammation (oxidative stress) and wound healing times in patients with burns, ${ }^{35}$ and to have an anti-inflammatory effect when used in periapical surgery which was attributed to an inhibitory effect on leukocyte chemotaxis and extravasation. ${ }^{36}$ The antimicrobial activity of PVP-iodine arises from its strong oxidizing effects which cause coagulation of nuclear material and pore formation in cells walls of bacteria and fungi. ${ }^{37}$ This mechanism of action explains why PVP-iodine is not associated with development of bacterial resistance. ${ }^{38}$ In contrast, resistance is commonly observed with antibiotics which act via specific biochemical pathways due to de novo mutations or acquisition of resistance genes from other organisms which overcome the antibiotic mechanism of action. ${ }^{39}$ PVP-iodine has clinical activity against a range of antibiotic-resistant bacteria and at therapeutic concentrations is superior to several other antiseptic agents. ${ }^{40}$ Liposomal PVP-iodine (3\%) hydrogel has been shown to be well tolerated, effective against biofilm formation, and have wound healing properties. ${ }^{41-43}$

The aim of this preliminary pilot study was to examine the potential utility of liposomal PVP-iodine (3\%) hydrogel as a novel treatment for common inflammatory skin conditions associated with bacterial colonization: acne vulgaris, atopic dermatitis, impetigo contagiosa, and rosacea.

\section{Methods}

\section{Patients and study design}

This prospective, single-arm (uncontrolled), open-label Phase II pilot study was performed at the Department of Dermatology, Clinic St. Urban, Freiburg, Germany (in conjunction with the University Clinics of Freiburg, Germany). Patients $\geq 18$ years with the following diseases were recruited from inpatient and outpatient clinics: acne vulgaris (comedonic and/or papular and pustular types), atopic dermatitis, impetigo contagiosa, and rosacea papulo-pustulosa. Exclusion criteria included diagnoses of dermatitis herpetiformis, hyperthyroidism, or other thyroid diseases; allergies to iodine, PVP-iodine, or excipients of the study medication; radioiodine treatment or diagnostic use of radioiodine $\leq 4$ weeks prior to study entry or $\leq 4$ weeks after study end; lithium therapy; and use of topical antibiotics, corticosteroids, or antiseptics $\leq 1$ day prior to receiving study medication. Concomitant medications were permitted during the study with the exception of the following: acne vulgaris (topical benzoyl peroxide gels, topical retinoids, topical acelaine acid, and systemic retinoids); atopic dermatitis (topical immunosuppressive agents); and rosacea (topical metronidazole and systemic retinoids). Pregnant or breastfeeding women were also excluded.

Following a baseline screening visit (conducted prior to study treatment to assess eligibility and to document medical history, demographic and disease characteristics), patients attended weekly study visits for 4 weeks (acne vulgaris and rosacea) or 2 weeks (atopic dermatitis and impetigo contagiosa). Patients were advised to apply a thin smear of 
liposomal PVP-iodine (3\%) hydrogel to the skin area under assessment using a single-use wooden spatula. Patients with acne vulgaris applied study medication once daily for 4 weeks, after washing their face with mild soap and water. Following a 15-minute application, the study medication was removed from the skin with water. Other patients applied the study medication several times a day for 2 weeks (atopic dermatitis and impetigo contagiosa) or 4 weeks (rosacea), according to each individual's skin condition. Treatment with study medication began on the same day as the screening visit, or 1 day later if a washout period was required due to nonpermitted concomitant medications. The treatment regimen in this pilot study was based on the anticipated duration of skin penetration, ${ }^{34}$ length of time for which an effect may be observed, and practical aspects including anticipated compliance.

This study was performed in accordance with the Declaration of Helsinki (version October 2000), good clinical practice recommendations, and the German Arzneimittelgesetz (Medicinal Products Act). The study protocol was also approved by the local ethics committee (Ethik-Kommission Universitätsklinikum Freiburg), and all patients provided informed, written consent.

\section{Outcomes and assessments}

Baseline disease characteristics and medical history were assessed at screening. Vital signs, pain score, plasma thyroid-stimulating hormone levels, and bacterial swabs of the treatment site (except for patients with acne vulgaris) were assessed at screening and at study end (data not shown), while the use of concomitant medications was documented at each study visit.

No primary end point was planned. The efficacy of liposomal PVP-iodine hydrogel was of particular interest, which was assessed using the Global Clinical Severity score. This was calculated at each study visit as the mean of diseasespecific scores for individual symptoms. Affected skin areas and clinical symptom severity were each rated on a numeric analog scale $(1=$ not at all, $2=$ a little, $3=$ fairly, $4=$ strongly, $5=$ very strongly). The following symptoms were assessed: acne (erythema, papules, comedones, pustules, teleangiectasia, and seborrhea, based on Modified Nottingham Acne Score); atopic dermatitis (erythema, induration, excoriation, lichenification, exudation, and itching); impetigo contagiosa (erythema, postulation, erosion, crusts, and exudation), and rosacea (erythema, papules, pustules, teleangiectasia, and seborrhea).
Other outcomes included Eczema Area and Severity Index (EASI) score (0-72), obtained at each study visit for patients with atopic dermatitis. ${ }^{44}$ Four body regions (head and neck, trunk, upper limbs, lower limbs) were assigned an area score based on the percentage of skin affected $(0=$ none to $6=90 \%-100 \%$ ) and severity (sum of erythema, induration, excoriation, and lichenification, each assessed on a four-point scale: $0=$ none to $3=$ severe). Pain and quality of life were documented in all patients at each study visit using a visual analog scale $(0=$ no pain to $100=$ worst pain $)$ and the validated Freiburg Life Quality Assessment (FLQA) core questionnaire, respectively. ${ }^{45}$ Patient and physician clinical global assessment of study treatment was performed at each study visit using a seven-point numeric analog scale ( $1=$ very good to $7=$ very poor). Safety was assessed throughout the study via documentation of adverse events and serious adverse events, in accordance with the World Health Organization's Adverse Reaction Terminology List. Patient compliance with study treatment was also assessed at each study visit.

\section{Statistical methods}

Baseline demographic and disease characteristics as well as safety outcomes were analyzed in the safety population. Efficacy variables were analyzed in the intent-to-treat population (all patients who received $\geq 1$ dose of study medication and with $\geq 1$ post-screening study visit).

Statistical analyses were performed for Global Clinical Severity score only. Change from baseline to end of treatment was assessed using Wilcoxon signed rank test for ordinal pairwise differences $(\alpha=5.0 \%)$. Descriptive analyses of other outcomes were performed.

As this pilot study aimed to provide the first assessment of liposomal PVP-iodine hydrogel treatment for chronic infective, inflammatory dermatoses, the study design did not include a formal calculation of sample size. A cohort of 70 patients (acne vulgaris $[n=30]$, atopic dermatitis $[n=20]$, rosacea $[n=10]$, and impetigo contagiosa $[n=10])$ remaining in the study for at least 2-4 weeks was estimated to provide sufficient preliminary evidence for the efficacy and tolerability of liposomal PVP-iodine hydrogel across the dermatoses under investigation and help to guide the design of future studies.

\section{Results}

\section{Patient characteristics}

Seventy patients received liposomal PVP-iodine hydrogel between May 2002 and December 2002, and 62 patients 
completed the planned durations of study treatment. Four patients (acne vulgaris $[n=1]$, atopic dermatitis $[n=2]$, impetigo contagiosa $[n=1]$ ) discontinued the study treatment prematurely, and final study visit data were missing for four patients (acne vulgaris $[n=1]$, atopic dermatitis $[n=2]$, impetigo contagiosa [n=1]; Figure 1).

Demographic and disease characteristics are summarized in Table 1. Individuals with acne vulgaris tended to be younger (median age 23.0 years) compared to those with atopic dermatitis, impetigo contagiosa, and rosacea (median age 41.5-60.0 years). There was a trend for patients with atopic dermatitis and impetigo contagiosa to have more concomitant illnesses and to be taking more medications compared with the acne vulgaris and rosacea groups. Most patients had a body mass index within the normal range, and all were Caucasian, with the exception of one patient with impetigo contagiosa who was Asian. No patients had a history of alcohol abuse and 37\% were current smokers.

Systemic prednisolone was the most common concomitant medication $(n=10)$. Other common concomitant systemic medications included antihistamines (clemastine hydrogen fumarate $[n=3]$, fexofenadine $[n=2]$ ), antibiotics (cefotiam, ciprofloxacin, doxycycline, each $n=1)$, and cyclosporine $(n=3)$.

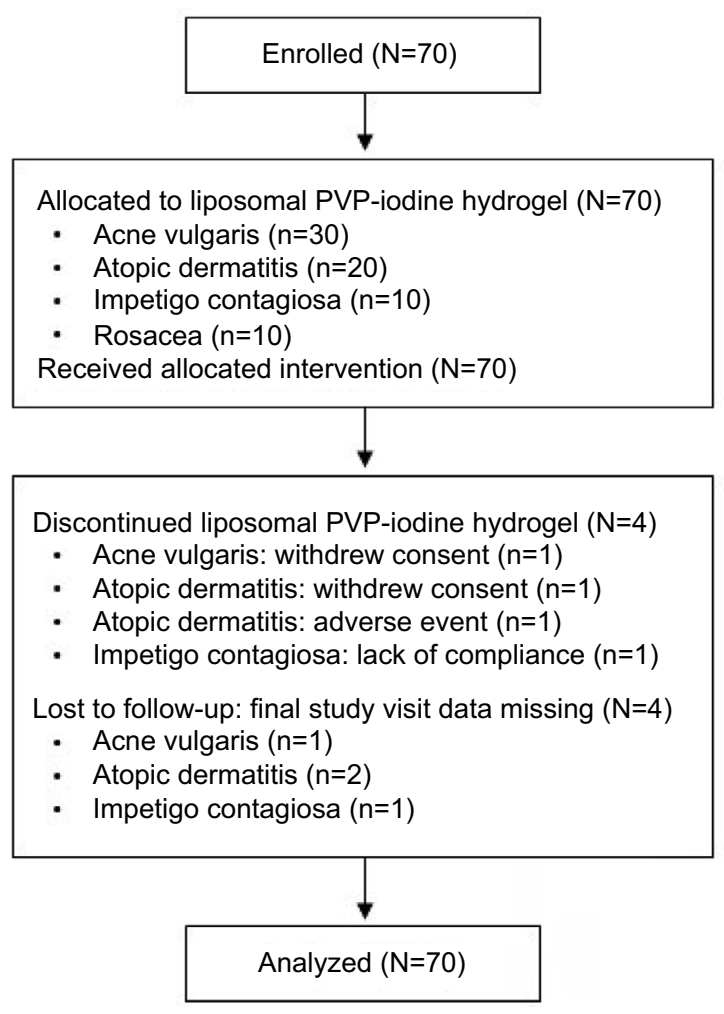

Figure I Disposition of enrolled patients.

Notes: Outcomes were analyzed in the intent-to-treat population $(\mathrm{N}=70)$ Abbreviation: PVP, polyvinylpyrrolidone.
Commonly used topical concomitant medications included tacrolimus $(\mathrm{n}=3)$, antifungal agents (clioquinol and selenium disulphide, both $n=1$ ), and antibacterial agents/antibiotics (benzoyl peroxide and isotretinoin erythromycin, both $n=1$ ).

Baseline mean (SD) Global Clinical Severity scores ranged from $2.3(0.3)$ for patients with acne vulgaris to 3.0 $(0.5)$ for patients with impetigo contagiosa. The following skin areas were treated with study medication and assessed: acne vulgaris (cheeks $[n=18,60 \%$ ], forehead $[n=6,20 \%]$, perioral area and chin $[n=2,7 \%]$, back $[n=3,10 \%]$, and breast $[n=1,3 \%]$ ); atopic dermatitis (arms $[n=9,45 \%]$, legs $[\mathrm{n}=3,15 \%]$, foot $[\mathrm{n}=2,10 \%]$, back $[\mathrm{n}=2,10 \%]$, elbow, breast, shoulder, and neck [each, $\mathrm{n}=1,5 \%]$ ); impetigo contagiosa (nose, chin, leg, arm, elbow, finger, shoulder, breast, abdomen, and axilla [each $n=1,10 \%]$ ); and rosacea (nose $[n=4$, $40 \%$ ], cheeks [ $n=4,40 \%]$, and forehead $[n=2,20 \%])$. Swabs collected at baseline and end of study treatment indicated no unanticipated bacteria were present on the skin sites treated with the study medication.

\section{Efficacy and quality of life outcomes}

Compared with baseline scores, Clinical Severity Scores of the individual symptoms for the four infective dermatoses investigated were lower following treatment with study medication (Table 2). Statistically significant improvements in Global Clinical Severity score were observed from baseline to end of study treatment for all dermatologic conditions (Figure 2). The median change in Global Clinical Severity score from baseline ranged from 0.5 for patients with acne vulgaris $(p<0.001)$ to 1.0 for patients with impetigo contagiosa ( $p=0.011)$. These changes in Global Clinical Severity score are supported by clinically relevant improvements in inflammation, wound healing, and infection from baseline to Week 2 of treatment, evident from patient photographs (Figure 3).

Improvements in all individual EASI scores, assessed for patients with atopic dermatitis only, were observed (Table 3). EASI global score decreased from a mean (SD) of 5.8 (2.6) at baseline to 4.8 (2.4) at final visit. For patients with rosacea, the total mean (SD) number of papules counted on the face was lower at the end of study treatment (17.8 [16.4]) compared with baseline (43.0 [26.6]). Also, with the exception of rosacea (for which patients reported no pain at baseline), pain intensity diminished during the course of study treatment (Table 4). Highest baseline mean (SD) pain scores were observed in patients with impetigo contagiosa (17.0 [25.4]) and were reduced by $\sim 60 \%$ by the end of study treatment $(6.7[13.2])$. 
Table I Patient demographic and disease characteristics at baseline

\begin{tabular}{|c|c|c|c|c|c|}
\hline \multirow[t]{2}{*}{ Parameter } & \multicolumn{5}{|c|}{ Infective dermatoses } \\
\hline & $\begin{array}{l}\text { Acne vulgaris } \\
(\mathrm{n}=30)\end{array}$ & $\begin{array}{l}\text { Atopic dermatitis } \\
(n=20)\end{array}$ & $\begin{array}{l}\text { Impetigo } \\
\text { contagiosa }(n=10)\end{array}$ & $\begin{array}{l}\text { Rosacea } \\
(n=10)\end{array}$ & $\begin{array}{l}\text { All patients } \\
(\mathrm{N}=70)\end{array}$ \\
\hline Median age, years (range) & $23.0(18.0-47.0)$ & $45.0(18.0-72.0)$ & $41.5(28.0-79.0)$ & $60.0(32.0-82.0)$ & $34.0(18.0-82.0)$ \\
\hline Female, n (\%) & $24(80)$ & $10(50)$ & $4(40)$ & $6(60)$ & $44(63)$ \\
\hline Median BMI, kg/m² (range) & $20.2(17.3-28.3)$ & $23.6(20.1-31.9)$ & $25.8(17.8-54.5)$ & $24.7(21.0-27.9)$ & $22.5(17.3-54.5)$ \\
\hline \multicolumn{6}{|l|}{ Smoking habits, n (\%) } \\
\hline Never smoker & $18(60)$ & $8(40)$ & $3(30)$ & $8(80)$ & $37(53)$ \\
\hline Exsmoker & $I(3)$ & $2(10)$ & $2(20)$ & $2(20)$ & $7(10)$ \\
\hline Current smoker & II (37) & $10(50)$ & $5(50)$ & 0 & $26(37)$ \\
\hline Presence of $\geq$ I concomitant disease, $n(\%)$ & $22(73)$ & $20(100)$ & $9(90)$ & $7(30)$ & $58(83)$ \\
\hline $\begin{array}{l}\text { Number of concomitant illnesses, } \\
\text { median (range) }\end{array}$ & I (0-5) & $3(1-9)$ & $3(0-10)$ & $I(0-5)$ & $2(0-10)$ \\
\hline \multicolumn{6}{|l|}{$\begin{array}{l}\text { Concomitant medications for the infective } \\
\text { dermatosis under investigation, } \mathrm{n}(\%)\end{array}$} \\
\hline Adapalene & I (3) & 0 & 0 & 0 & $\mathrm{I}(\mathrm{I})$ \\
\hline Benzoyl peroxide & I (3) & 0 & 0 & 0 & $I(I)$ \\
\hline Betamethasone & 0 & I (5) & 0 & 0 & $\mathrm{I}(\mathrm{I})$ \\
\hline Calcium dobesilate & 0 & 0 & 0 & $\mathrm{I}(10)$ & $\mathrm{I}(\mathrm{I})$ \\
\hline Cefotiam & 0 & 0 & $\mathrm{I}(10)$ & 0 & $I(I)$ \\
\hline Cyclosporine & 0 & $3(15)$ & 0 & 0 & $3(4)$ \\
\hline Ciprofloxacin a & 0 & I (5) & 0 & 0 & $I(I)$ \\
\hline Clemastine hydrogen fumarate ${ }^{b}$ & 0 & $3(15)$ & 0 & 0 & $3(4)$ \\
\hline Clioquinol & 0 & 0 & $I(10)$ & 0 & $\mathrm{I}(\mathrm{I})$ \\
\hline Doxycycline & 0 & 0 & 0 & $I(10)$ & $I(I)$ \\
\hline Fexofenadine & 0 & $2(10)$ & 0 & 0 & $2(3)$ \\
\hline Isotretinoin erythromycin & I (3) & 0 & 0 & 0 & $I(I)$ \\
\hline Linolic acid & 0 & I (5) & 0 & 0 & $I(I)$ \\
\hline Prednisolone (systemic) & 0 & $4(20)^{\mathrm{e}}$ & $5(50)$ & $I(10)$ & $10(14)$ \\
\hline Selenium disulphide & 0 & I (5) & 0 & 0 & I (I) \\
\hline Soya bean oil & 0 & I (5) & 0 & 0 & $I(I)$ \\
\hline Tacrolimus $^{c}$ & 0 & $3(15)$ & 0 & 0 & $3(4)$ \\
\hline Unlisted & 0 & I (5) & 0 & $I(10)$ & $2(3)$ \\
\hline $\begin{array}{l}\text { Baseline Clinical Global Severity score, } \\
\text { mean (SD) }\end{array}$ & $2.3(0.3)$ & $2.8(0.5)$ & $3.0(0.5)$ & $2.9(0.4)$ & NR \\
\hline
\end{tabular}

Notes: a Ciprofloxacin was given to a patient with superinfected atopic dermatitis. ${ }^{b}$ Atopic dermatitis and allergic rhinitis ( $n=l$ ). ${ }^{\mathrm{c}}$ For one of the three patients receiving

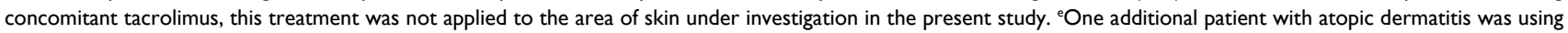
topical prednisolone cream at screening, but due to missing data it is unclear if this medication was continued during the study. ${ }^{\mathrm{d}}$ Mean baseline Global Clinical Severity score represents different clinical symptoms for the skin area treated with study medication, rated on a five-point numerical analog scale $(I=$ not at all to $5=$ very strongly).

Abbreviations: NR, not reported; BMI, body mass index.

FLQA domain scores were slightly lower at Week 2 of study treatment compared with baseline (end of treatment for patients with atopic dermatitis and impetigo contagiosa). Further reductions were observed in all domains except "mental health" at Week 4 of the study treatment (end of treatment for patients with acne vulgaris and rosacea; Figure S1).

Data indicated that all patients were compliant with study medication throughout the study. Overall, patients' mean (SD) global assessment of study medication at final visit was $2.8(0.9)$. Highest values were reported by patients with atopic dermatitis (3.3 [1.0]) and lowest values were reported by patients with impetigo (2.1 [0.9]). Similar global assessments of efficacy were reported by physicians: overall (2.9
[0.9]), highest for atopic dermatitis (3.3 [0.9]) and lowest for impetigo (2.3 [1.0]).

\section{Safety outcomes}

In total, 26 patients (37\%) reported 34 adverse events during the course of the study. The most frequent all-causality adverse events were burning sensation or itching at the skin area following application of study medication $(\mathrm{n}=10$ [14\%] and $n=6[9 \%]$, respectively; Table 5). Two patients, both with impetigo contagiosa, discontinued study medication due to local skin reactions following application of study medication: one patient experienced moderate itching, dry skin, and mild burning, while the second patient experienced dry 
Table 2 Clinical severity of individual symptoms assessed in the skin areas treated with study medication (patients with available data)

\begin{tabular}{lll}
\hline Disease symptoms & \multicolumn{2}{l}{ Clinical Severity score } \\
\cline { 2 - 3 } & \multicolumn{1}{l}{ Baseline } & Final visit \\
\cline { 2 - 3 } & Median (range) & Median (range) \\
\hline Acne vulgaris & & \\
Erythema & $3.0(2-4)$ & $2.0(\mathrm{I}-3)$ \\
Papules & $3.0(2-5)$ & $2.0(\mathrm{I}-4)$ \\
Comedones & $2.0(\mathrm{I}-4)$ & $2.0(\mathrm{I}-3)$ \\
Pustules & $2.0(\mathrm{I}-4)$ & $\mathrm{I} .0(\mathrm{I}-3)$ \\
Telangiectasia & $\mathrm{I} .0(\mathrm{I}-2)$ & $\mathrm{I} .0(\mathrm{I}-2)$ \\
Seborrhoea & $2.0(\mathrm{I}-4)$ & $2.0(\mathrm{I}-3)$ \\
Atopic dermatitis & & \\
Erythema & $3.0(2-4)$ & $2.0(2-4)$ \\
Induration & $3.0(2-4)$ & $3.0(\mathrm{I}-4)$ \\
Excoriation & $3.0(2-4)$ & $2.0(\mathrm{I}-4)$ \\
Lichenification & $3.0(2-4)$ & $3.0(2-4)$ \\
Exudation & $2.0(\mathrm{I}-3)$ & $\mathrm{I} .0(\mathrm{I}-2)$ \\
Itching & $3.0(2-4)$ & $2.0(\mathrm{I}-5)$ \\
Impetigo contagiosa & & \\
Erythema & $3.4(\mathrm{I}-4)$ & $2.0(\mathrm{I}-3)$ \\
Pustulation & $2.5(\mathrm{I}-5)$ & $\mathrm{I} .0(\mathrm{I}-3)$ \\
Erosion & $3.5(2-5)$ & $2.0(\mathrm{I}-4)$ \\
Crusts & $4.0(\mathrm{I}-5)$ & $2.0(\mathrm{I}-4)$ \\
Exudation & $2.0(2-4)$ & $2.0(\mathrm{I}-3)$ \\
Rosacea & & \\
Erythema & $4.0(\mathrm{I}-4)$ & $3.0(\mathrm{I}-3)$ \\
Papules & $3.5(2-4)$ & $3.0(\mathrm{I}-4)$ \\
Pustules & $3.0(2-4)$ & $\mathrm{I} .5(\mathrm{I}-3)$ \\
Telangiectasia & $2.0(\mathrm{I}-3)$ & $2.0(\mathrm{I}-2)$ \\
Seborrhea & $2.0(2-3)$ & $2.0(2-2)$ \\
\hline Notes Clnca & & \\
& &
\end{tabular}

Notes: Clinical Severity scores were rated on a five-point numerical analog scale ( $I=$ not at all to $5=$ very strongly)

skin and mild burning. These events resolved completely and were considered possibly related to study medication. Of the two patients with elevated thyroid-stimulating hormone levels, this was considered clinically relevant in one patient (baseline: $2.9 \mathrm{mIU} / \mathrm{L}$ to final visit: $5.1 \mathrm{mIU} / \mathrm{L}$; normal range 0.1-4.0 mIU/L) and described as mild and unlikely to be related to study medication. One serious adverse event of syncope was also reported. The patient was hospitalized for 4 days (investigations performed were inconclusive) and recovered without sequelae. The event was considered unrelated to study medication and did not result in study treatment discontinuation or interruption. No deaths occurred during the study.

\section{Discussion}

This uncontrolled pilot study was designed as a preliminary investigation of the potential usefulness of liposomal PVPiodine hydrogel as a treatment for infective dermatoses.
It demonstrated that liposomal PVP-iodine hydrogel can potentially provide effective treatment for a range of inflammatory skin diseases associated with bacterial colonization. Following short-term treatment for 2 or 4 weeks, statistically significant improvements were observed in Global Clinical Severity scores for patients with acne vulgaris, atopic dermatitis, impetigo contagiosa, and rosacea. Ordinal scales are widely used and accepted for global clinical assessments and to capture symptom severity in numerous settings, including dermatology and pain. ${ }^{46,47}$ This supports the reliability and validity of the improved Global Clinical Severity scores observed in this study. Clinically meaningful improvements in disease-specific symptoms were also observed, including a full categorical (1 point) decrease in the widely used and validated EASI global score in patients with atopic dermatitis, ${ }^{48,49}$ over twofold improvement in the number of facial papules in patients with rosacea, and a 2.5 -fold reduction in pain intensity for patients with impetigo contagiosa, the most painful dermatosis at baseline in this study. These improvements in Global Clinical Severity and disease-specific scores reflect the observed gains from baseline in patients' quality of life, indicated by reductions in FLQA domain scores. While these efficacy outcomes cannot be compared with other agents due to differences in study design and patient populations, the response to liposomal PVP-iodine hydrogel exceeded the outcome anticipated by the investigators, based on prior observations with standard treatments in similar cases. Recent head-to-head trials provide some insight into the efficacy of topical agents, albeit with different treatment schemes and durations (topical azelaic acid for 15 weeks resulted in $\leq 1.7$-fold decrease in rosacea inflammatory lesions, and a 1.8-point reduction in EASI score following 2 months of emollient and topical corticosteroid use has been reported)..$^{50,51}$

Liposomal PVP-iodine hydrogel was well tolerated by most patients, including those with conditions commonly associated with sensitive skin such as atopic dermatitis and rosacea. This may be because only relatively low concentrations of PVP-iodine (3\%) are required in the liposomal hydrogel formulation for an antiseptic effect, which is in contrast to case reports of allergic reaction with non-liposome formulation of PVP-iodine in patients with infective, inflammatory dermatoses. ${ }^{52}$ The most commonly reported adverse events were a burning sensation (14\%) or itching (9\%) following the application of study medication. Two patients discontinued the study treatment due to local skin reactions which were considered possibly related to study medication. It is possible that these symptoms relate to the iodine in the 
Median (95\% Cl), p-value

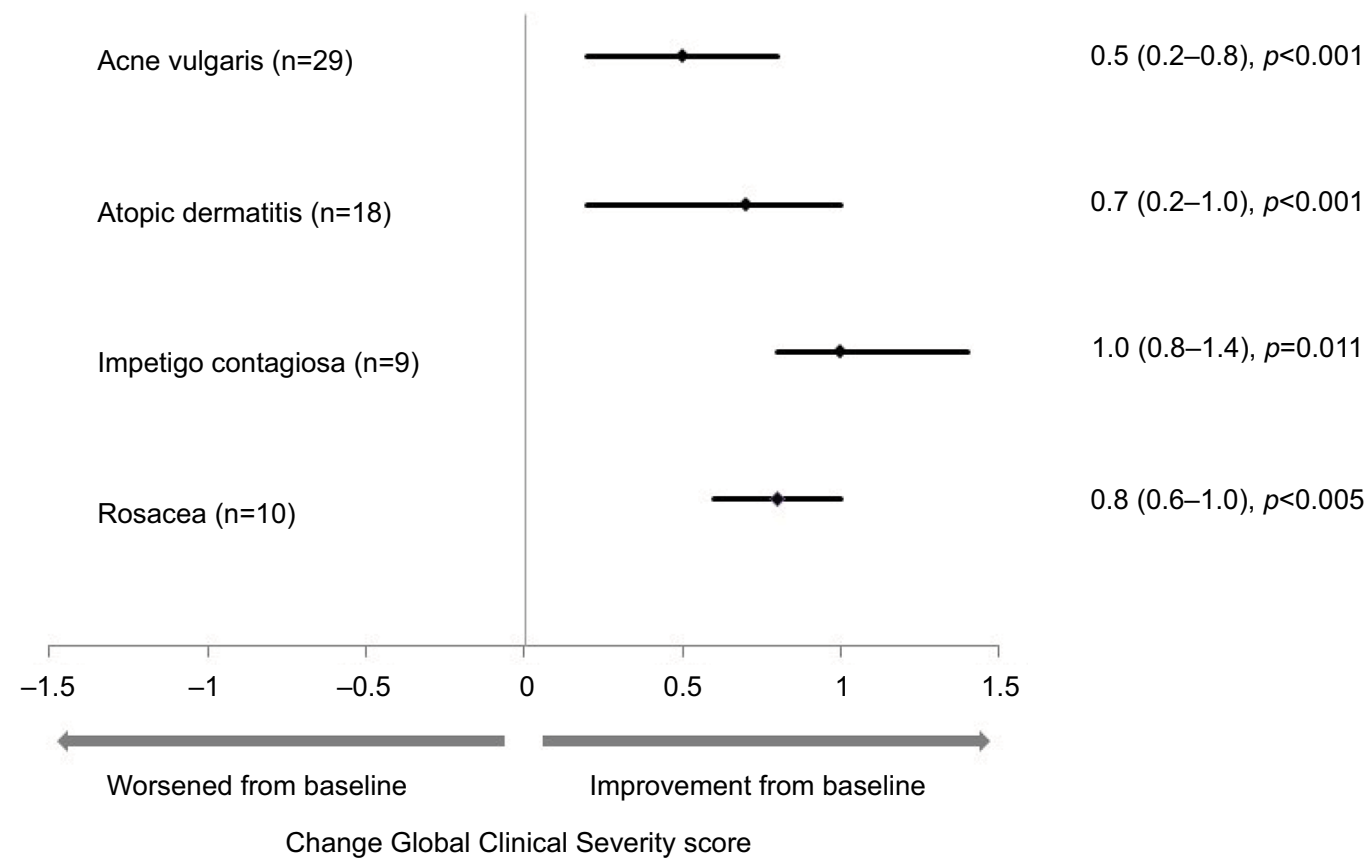

Figure 2 Change in Global Clinical Severity scores from baseline to end of treatment.

Notes: Global Clinical Severity score was the mean score of different clinical symptoms for the skin area treated with study medication and rated on a five-point numerical analog scale $(I=$ not at all to $5=$ very strongly). Median (range) Global Severity scores at baseline and final visit were: acne vulgaris (2.3 [I.5, 2.8], I.7 [I.2, 2.8]); atopic dermatitis (2.8 [2.0, 3.7], 2.2 [1.5, 3.2]); impetigo contagiosa (3.2 [2.2, 3.6], I.8 [1.0, 2.6]); and rosacea (2.9 [2.2, 3.6], 2.I [0I.6, 2.8]). Statistical analysis was performed using Wilcoxon signed-rank test.

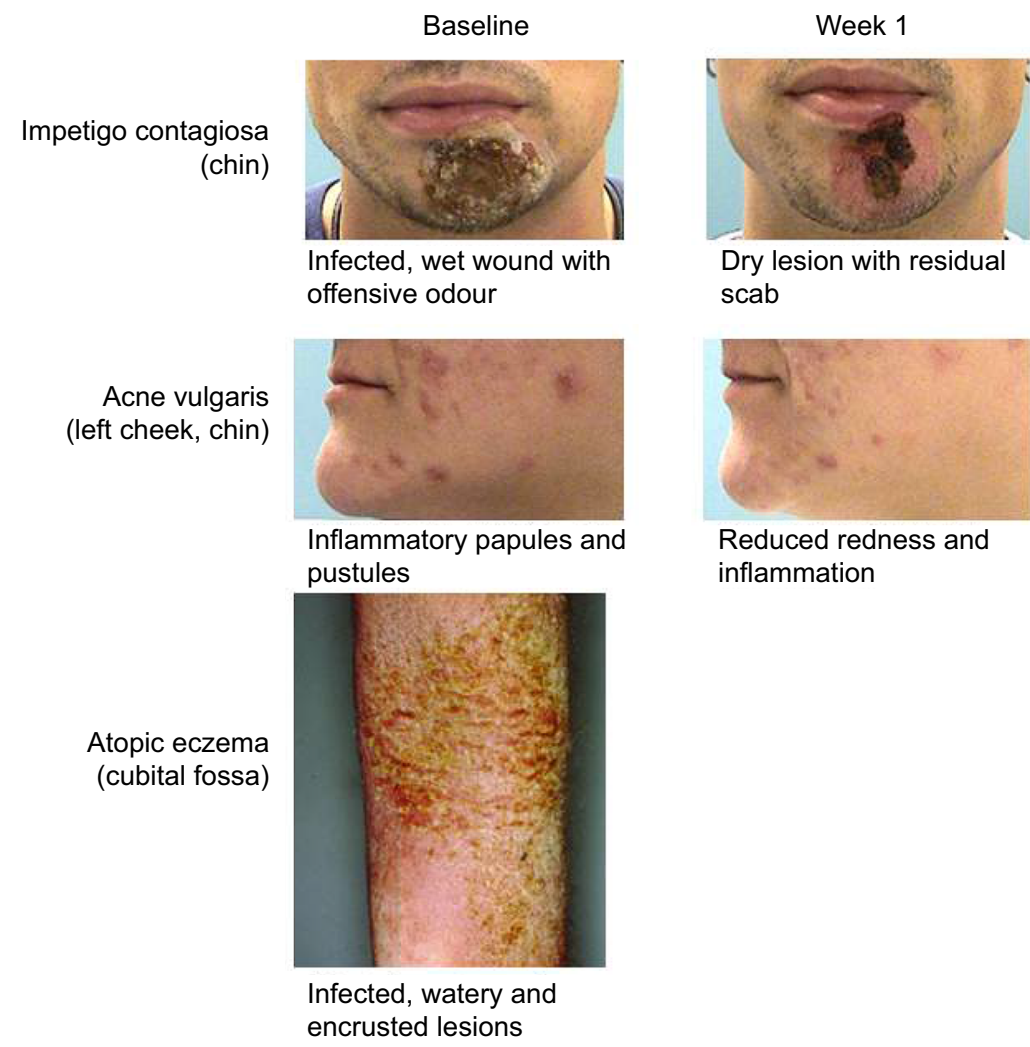

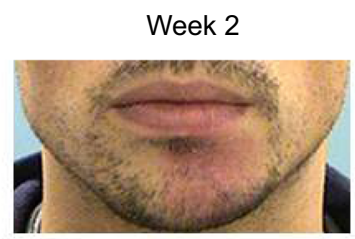

Wound healed, some redness of skin

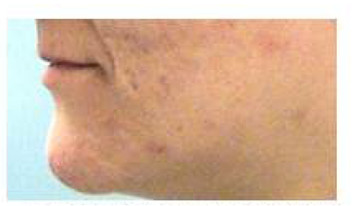

Lesions healed. No pustules, papules or inflammation

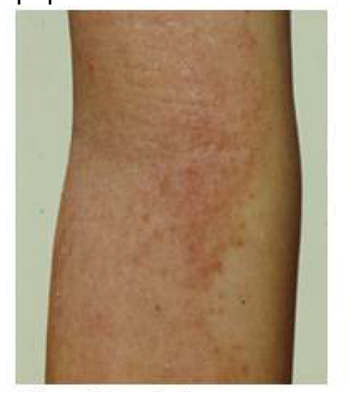

Wound healed, no wet or infected lesions

Figure 3 Impact of liposomal PVP-iodine (3\%) hydrogel on treated skin areas.

Notes: Photographs of representative patients with infective dermatoses at baseline and following I week and 2 weeks of study treatment.

Abbreviation: PVP, polyvinylpyrrolidone. 
studies have demonstrated that compared with standard treatments, liposomal PVP-iodine hydrogel enhanced epithelialization and reduced loss of skin grafts as well as resulting in faster complete healing of burn wounds and improved cosmetic outcomes. ${ }^{41,57,58}$ While the wound healing effects of liposomal PVP-iodine hydrogel undoubtedly relate to antisepsis, anti-inflammatory and moisturizing effects also play a role. The anti-inflammatory activity arises from the iodine component which was shown to interact with various stages of the inflammatory cascade in vitro, including scavenging superoxide anions, inhibiting production of reactive oxygen species by neutrophils, and stabilizing mast cells. ${ }^{59}$ This mechanism of action also explains the free-radical scavenging and improved oxidative stress parameters observed in burn wounds treated with liposomal PVP-iodine hydrogel. ${ }^{35}$ Furthermore, the moisture providing capacity and release of phospholipid molecules by hydrosomes into the wound tissue support cellular repair. ${ }^{41,58}$ The amphiphilic nature of phospholipids also permits dispersion of hydrophilic and lipophilic compounds without disturbing skin integrity. ${ }^{60,61}$ Based on its unique formulation and properties supporting skin penetration, antimicrobial efficacy, and wound healing, liposomal PVP-iodine hydrogel may be particularly suited as a treatment for the infected and inflammatory dermatoses investigated in this preliminary study.

This pilot study was associated with a number of limitations, including the small number of patients and short duration of study treatment. Absence of a placebo or active comparator group also limits the interpretation of efficacy outcomes. While patients experience fluctuations in symptom severity over time, significant improvements in Global Clinical Severity score observed in all the dermatoses studied strongly points to an efficacious effect of PVP-iodine hydrogel. A further limitation relates to the open-label design of this pilot study, in which patients were responsible for administering their own treatment; 8 of the 70 patients recruited did not receive the full course of liposomal PVP-iodine hydrogel ( $n=4$ discontinued study medication, $n=4$ lost to follow-up [final study data missing]). As analyses were based on the intent-to-treat population to reflect real-life clinical practice, a small number of patients were included who received nonpermitted medications. Clinical efficacy and safety of liposomal PVP-iodine hydrogel were the focus of this preliminary study, and infection was not assessed in detail since the antiseptic properties of PVP-iodine are well described. ${ }^{37,38,40}$ The purpose of the swabs was to provide a qualitative assessment of the bacterial species present. A valid, quantitative analysis of the impact of liposomal PVP-iodine hydrogel on bacterial load was not feasible, given the small number of patients and lack of a comparator group in this study. Also, while absorption of PVP-iodine from the liposomal hydrogel by the diseased skin types under investigation was not assessed, this was assumed to be lower than that previously reported in mucosa or wounds where no stratum corneum is present. However, the beneficial effects of liposomal PVP-iodine hydrogel in complex skin conditions were demonstrated in a study of split-thickness skin grafts which represent different skin depths likely present in patients in the present study. ${ }^{62}$

The preliminary findings from this pilot study can be used to inform the design of larger scale studies, including randomized, controlled trials in order to assess the impact of treatment on bacterial load and elucidate how the clinical benefit of liposomal PVP-iodine hydrogel can be maximized for patients with various types of inflammatory, infective dermatoses. Indeed, the design of an ongoing Phase II study of liposomal PVP-iodine hydrogel in patients with acne vulgaris utilized learnings from the present study (NCT02126709). The delay in publishing the findings from this pilot study reflects in part previous decreased interest in the wider scientific community regarding new treatment approaches for infected, inflammatory dermatoses.

In summary, liposomal PVP-iodine hydrogel has potential utility as a treatment with a novel mode of action for various inflammatory skin conditions associated with bacterial colonization. In this small-scale study, liposomal PVP-iodine hydrogel improved disease-related symptoms and Global Clinical Severity scores of acne vulgaris, atopic dermatitis, impetigo contagiosa, and rosacea. The complex pathophysiology of inflammatory, infective dermatoses necessitates a multifaceted treatment approach directed at healing the skin barrier, managing microbial colonization, and addressing immune dysfunction. Due to its unique mode of action and good tolerability profile, liposomal PVP-iodine hydrogel may represent a useful addition to the current armamentarium of treatments available to manage these difficult-to-treat skin diseases.

\section{Acknowledgments}

This study was funded by Mundipharma Research $\mathrm{GmbH}$ \& Co.KG. Medical writing support was provided by Siân Marshall (PhD) of Siantifix Ltd, Cambridgeshire, UK, funded by Mundipharma Research GmbH \& Co.KG.

\section{Author contributions}

All authors participated in the acquisition, analysis, and/ or interpretation of the data reported in this paper and had 
access to the primary clinical study data. MA and SM collected clinical data; BB and MH made substantial contributions to the analysis and interpretation of the study results; LG and AJ provided input into the interpretation of the data. All authors contributed to the drafting of the manuscript and/or critical review of the content and all approved the submitted paper.

\section{Disclosure}

Matthias Augustin has served as consultant/paid speaker for and/or participated in clinical trials sponsored by the following companies which manufacture drugs used to treat dermatological diseases: Abbott, Almirall, Amgen, Biogen (Idec), Celgene, Centocor, Janssen-Cilag, Leo, Medac, Mundipharma, MSD (formerly Essex, Schering-Plough), Novartis, and Pfizer (formerly Wyeth). Bjoern Bosse, Michael Hopp, and Stefan Mueller are employees of Mundipharma Research GmbH \& Co.KG. Arnd Jacobi has served as an invited speaker for Abbott, Biogen (Idec), Celgene, Janssen-Cilag, Leo, Novartis and Pfizer (formerly Wyeth). Lisa Goepel participated in clinical trials and/or received non-financial support sponsored by the following companies which manufacture drugs used to treat dermatological diseases: Abbott, Biogen (Idec), Celgene, Janssen-Cilag, Novartis. The authors report no other conflicts of interest related to this work.

\section{References}

1. Hay RJ, Johns NE, Williams HC, et al. The global burden of skin disease in 2010: an analysis of the prevalence and impact of skin conditions. $J$ Invest Dermatol. 2014;134(6):1527-1534.

2. Williams HC, Dellavalle RP, Garner S. Acne vulgaris. Lancet. 2012;379(9813):361-372.

3. Uslu G, Sendur N, Uslu M, Savk E, Karaman G, Eskin M. Acne: prevalence, perceptions and effects on psychological health among adolescents in Aydin, Turkey. J Eur Acad Dermatol Venereol. 2008;22(4):462-469.

4. Aksoy B, Altaykan-Hapa A, Egemen D, Karagoz F, Atakan N. The impact of rosacea on quality of life: effects of demographic and clinical characteristics and various treatment modalities. Br J Dermatol. 2010;163(4):719-725.

5. Kiebert G, Sorensen SV, Revicki D, et al. Atopic dermatitis is associated with a decrement in health-related quality of life. Int J Dermatol. 2002;41(3):151-158.

6. Watkins P. Impetigo: aetiology, complications and treatment options. Nurs Stand. 2005;19(36):50-54.

7. Ayer J, Burrows N. Acne: more than skin deep. Postgrad Med J. 2006;82(970):500-506.

8. Ong PY, Leung DY. The infectious aspects of atopic dermatitis. Immunol Allergy Clin North Am. 2010;30(3):309-321.

9. Boguniewicz M, Leung DY. Recent insights into atopic dermatitis and implications for management of infectious complications. J Allergy Clin Immunol. 2010;125(1):4-13.

10. Breuer K, Wittmann M, Kempe K, et al. Alpha-toxin is produced by skin colonizing Staphylococcus aureus and induces a T helper type 1 response in atopic dermatitis. Clin Exp Allergy. 2005;35(8):1088-1095.

11. Koning S, van der Sande R, Verhagen AP, et al. Interventions for impetigo. Cochrane Database Syst Rev. 2012;1:CD003261.
12. Pereira LB. Impetigo - review. An Bras Dermatol. 2014;89(2):293-299.

13. Jarmuda S, O’Reilly N, Zaba R, Jakubowicz O, Szkaradkiewicz A, Kavanagh K. Potential role of Demodex mites and bacteria in the induction of rosacea. J Med Microbiol. 2012;61(Pt 11):1504-1510.

14. Jarmuda S, McMahon F, Zaba R, et al. Correlation between serum reactivity to Demodex-associated Bacillus oleronius proteins, and altered sebum levels and Demodex populations in erythematotelangiectatic rosacea patients. J Med Microbiol. 2014;63(Pt 2):258-262.

15. Laquer V, Hoang V, Nguyen A, Kelly KM. Angiogenesis in cutaneous disease: part II. J Am Acad Dermatol. 2009;61(6):945-958.

16. Del Rosso JQ, Thiboutot D, Gallo R, et al. Consensus recommendations from the American Acne \& Rosacea Society on the management of rosacea, part 2: a status report on topical agents. Cutis. 2013;92(6): 277-284.

17. Del Rosso JQ, Thiboutot D, Gallo R, et al. Consensus recommendations from the American Acne \& Rosacea Society on the management of rosacea, part 5: a guide on the management of rosacea. Cutis. 2014;93(3): $134-138$.

18. Eichenfield LF, Tom WL, Berger TG, et al. Guidelines of care for the management of atopic dermatitis: section 2. Management and treatment of atopic dermatitis with topical therapies. J Am Acad Dermatol. 2014;71(1):116-132.

19. Purdy S, de BD. Acne vulgaris. Clin Evid (Online). 2011;2011:1714.

20. Reinholz M, Tietze JK, Kilian K, et al. Rosacea - S1 guideline. J Dtsch Dermatol Ges. 2013;11(8):768-780.

21. Sidbury R, Davis DM, Cohen DE, et al. Guidelines of care for the management of atopic dermatitis: section 3. Management and treatment with phototherapy and systemic agents. J Am Acad Dermatol. 2014;71(2): 327-349.

22. Nast A, Dreno B, Bettoli V, et al. European evidence-based (S3) guidelines for the treatment of acne. J Eur Acad Dermatol Venereol. 2012;26(Suppl 1):1-29.

23. Price D, Betancourt V, Kaufman L, Rodriguez JE. FPIN's clinical inquiries. Treatment of impetigo. Am Fam Physician. 2007;75(5):703-704.

24. Stevens DL, Bisno AL, Chambers HF, et al. Practice guidelines for the diagnosis and management of skin and soft-tissue infections. Clin Infect Dis. 2005;41(10):1373-1406.

25. Nagaraju U, Bhat G, Kuruvila M, Pai GS, Jayalakshmi, Babu RP. Methicillin-resistant Staphylococcus aureus in community-acquired pyoderma. Int J Dermatol. 2004;43(6):412-414.

26. Alsterholm M, Flytstrom I, Bergbrant IM, Faergemann J. Fusidic acidresistant Staphylococcus aureus in impetigo contagiosa and secondarily infected atopic dermatitis. Acta Derm Venereol. 2010;90(1):52-57.

27. Ozolins M, Eady EA, Avery AJ, et al. Comparison of five antimicrobial regimens for treatment of mild to moderate inflammatory facial acne vulgaris in the community: randomised controlled trial. Lancet. 2004;364(9452):2188-2195.

28. Allen HB, Vaze ND, Choi C, et al. The presence and impact of biofilm-producing staphylococci in atopic dermatitis. JAMA Dermatol. 2014;150(3):260-265.

29. Metiko B, Brooks K, Burkhart CG, Burkhart CN, Morrell D. Is the current model for acne pathogenesis backwards? J Am Acad Dermatol. 2015;72(6):e167.

30. Coenye T, Peeters E, Nelis HJ. Biofilm formation by Propionibacterium acnes is associated with increased resistance to antimicrobial agents and increased production of putative virulence factors. Res Microbiol. 2007;158(4):386-392.

31. Reimer K, Fleischer W, Brogmann B, et al. Povidone-iodine liposomes: an overview. Dermatology. 1997;195(Suppl 2):93-99.

32. Chang HI, Yeh MK. Clinical development of liposome-based drugs: formulation, characterization, and therapeutic efficacy. Int J Nanomedicine. 2012;7:49-60.

33. Sugimoto K, Ishikawa N, Sugioka T, et al. The importance of disinfection therapy using povidone-iodine solution in atopic dermatitis. Dermatology. 2002;204(Suppl 1):63-69.

34. Khan SA. Observations in the treatment of acne vulgaris with a povidone iodine skin cleanser. Br J Clin Pract. 1979;33(10):289-290. 
35. Al-Kaisy AA, Salih SA. Role of the antioxidant effect of vitamin E with vitamin $\mathrm{C}$ and topical povidone-iodine ointment in the treatment of burns. Ann Burns Fire Disasters. 2005;18(1):19-30.

36. Kumar KS, Reddy GV, Naidu G, Pandiarajan R. Role of povidone iodine in periapical surgeries: Hemostyptic and anti-inflammatory? Ann Maxillofac Surg. 2011;1(2):107-111.

37. Schreier H, Erdos G, Reimer K, Konig B, Konig W, Fleischer W. Molecular effects of povidone-iodine on relevant microorganisms: an electron-microscopic and biochemical study. Dermatology. 1997;195(Suppl2):111-116.

38. Kunisada T, Yamada K, Oda S, Hara O. Investigation on the efficacy of povidone-iodine against antiseptic-resistant species. Dermatology. 1997;195(Suppl 2):14-18.

39. Tenover FC. Mechanisms of antimicrobial resistance in bacteria. Am J Infect Control. 2006;34(5 Suppl 1):S3-S10.

40. Fleischer W, Reimer K. Povidone-iodine in antisepsis-state of the art. Dermatology. 1997;195 Suppl 2:3-9.

41. Vogt PM, Reimer K, Hauser J, et al. PVP-iodine in hydrosomes and hydrogel - a novel concept in wound therapy leads to enhanced epithelialization and reduced loss of skin grafts. Burns. 2006;32(6):698-705.

42. Reimer K, Vogt PM, Broegmann B, et al. An innovative topical drug formulation for wound healing and infection treatment: in vitro and in vivo investigations of a povidone-iodine liposome hydrogel. Dermatology. 2000;201(3):235-241.

43. Hoekstra MJ, Westgate SJ, Mueller S. Povidone-iodine ointment demonstrates in vitro efficacy against biofilm formation. Int Wound J. 2017;14(1):172-179.

44. Hanifin JM, Thurston M, Omoto M, Cherill R, Tofte SJ, Graeber M. The eczema area and severity index (EASI): assessment of reliability in atopic dermatitis. EASI Evaluator Group. Exp Dermatol. 2001;10(1):11-18.

45. Augustin M, Lange S, Wenninger K, Seidenglanz K, Amon U, Zschocke I. Validation of a comprehensive Freiburg Life Quality Assessment (FLQA) core questionnaire and development of a threshold system. Eur J Dermatol. 2004;14(2):107-113.

46. Dworkin RH, Turk DC, Farrar JT, et al. Core outcome measures for chronic pain clinical trials: IMMPACT recommendations. Pain. 2005;113(1-2):9-19.

47. Feldman SR, Krueger GG. Psoriasis assessment tools in clinical trials. Ann Rheum Dis. 2005;64(Suppl 2):ii65-68; discussion ii69-73.

48. Schmitt J, Langan S, Williams HC. What are the best outcome measurements for atopic eczema? A systematic review. J Allergy Clin Immunol. 2007;120(6):1389-1398.

49. Barbier N, Paul C, Luger T, et al. Validation of the Eczema Area and Severity Index for atopic dermatitis in a cohort of 1550 patients from the pimecrolimus cream $1 \%$ randomized controlled clinical trials programme. Br J Dermatol. 2004;150(1):96-102.
50. Elewski BE, Fleischer AB, Jr., Pariser DM. A comparison of $15 \%$ azelaic acid gel and $0.75 \%$ metronidazole gel in the topical treatment of papulopustular rosacea: results of a randomized trial. Arch Dermatol. 2003;139(11):1444-1450.

51. Thomas KS, Bradshaw LE, Sach TH, et al. Silk garments plus standard care compared with standard care for treating eczema in children: a randomised, controlled, observer-blind, pragmatic trial (CLOTHES Trial). PLoS Med. 2017;14(4):e1002280.

52. Yoshida K, Sakurai Y, Kawahara S, et al. Anaphylaxis to polyvinylpyrrolidone in povidone-iodine for impetigo contagiosum in a boy with atopic dermatitis. Int Arch Allergy Immunol. 2008;146(2):169-173.

53. Bonowitz A, Schaller M, Laude J, Reimer K, Korting HC. Comparative therapeutic and toxic effects of different povidone iodine (PVP-I) formulations in a model of oral candidosis based on in vitro reconstituted epithelium. J Drug Target. 2001;9(1):75-83.

54. Balogh D, Bauer M, Riccabona G. The influence of povidone-iodine treatment on thyroid hormones in severe burns. J Hosp Infect. 1985;6 Suppl A:147-153.

55. Kovacikova L, Kunovsky P, Skrak P, Hraska V, Kostalova L, Tomeckova E. Thyroid hormone metabolism in pediatric cardiac patients treated by continuous povidone-iodine irrigation for deep sternal wound infection. Eur J Cardiothorac Surg. 2002;21(6):1037-1041.

56. Hagedorn M, Hauptmann S, Essinger U, Kaden P, Mittermayer C. [In vitro and in vivo studies of local disinfection and wound healing] Hautarzt. 1995;46(5):319-324. German.

57. Homann HH, Rosbach O, Moll W, et al. A liposome hydrogel with polyvinyl-pyrrolidone iodine in the local treatment of partial-thickness burn wounds. Ann Plast Surg. 2007;59(4):423-427.

58. Vogt PM, Hauser J, Rossbach O, et al. Polyvinyl pyrrolidone-iodine liposome hydrogel improves epithelialization by combining moisture and antisepis. A new concept in wound therapy. Wound Repair Regen. 2001;9(2):116-122.

59. Beukelman CJ, van den Berg AJ, Hoekstra MJ, Uhl R, Reimer K, Mueller $\mathrm{S}$. Anti-inflammatory properties of a liposomal hydrogel with povidoneiodine (Repithel) for wound healing in vitro. Burns. 2008;34(6): 845-855.

60. Mueller S, Vogt PM, Steinau HU, et al. Repithel: removing the barriers to wound healing. Dermatology. 2006;212(Suppl 1):77-81.

61. Lautenschlager H. Liposomes in dermatological preparations: Part II. Cosmet Toilet. 1990;105(7):63-72.

62. Hauser J, Rossbach O, Vogt PM, et al. [Efficacy of treatment with Repithel and Jelonet in comparison to treatment with Jelonet alone - a randomized clinical trial in patients receiving meshed skin grafts] Zentralbl Chir. 2006;131(4):315-321. German. 


\section{Supplementary material}

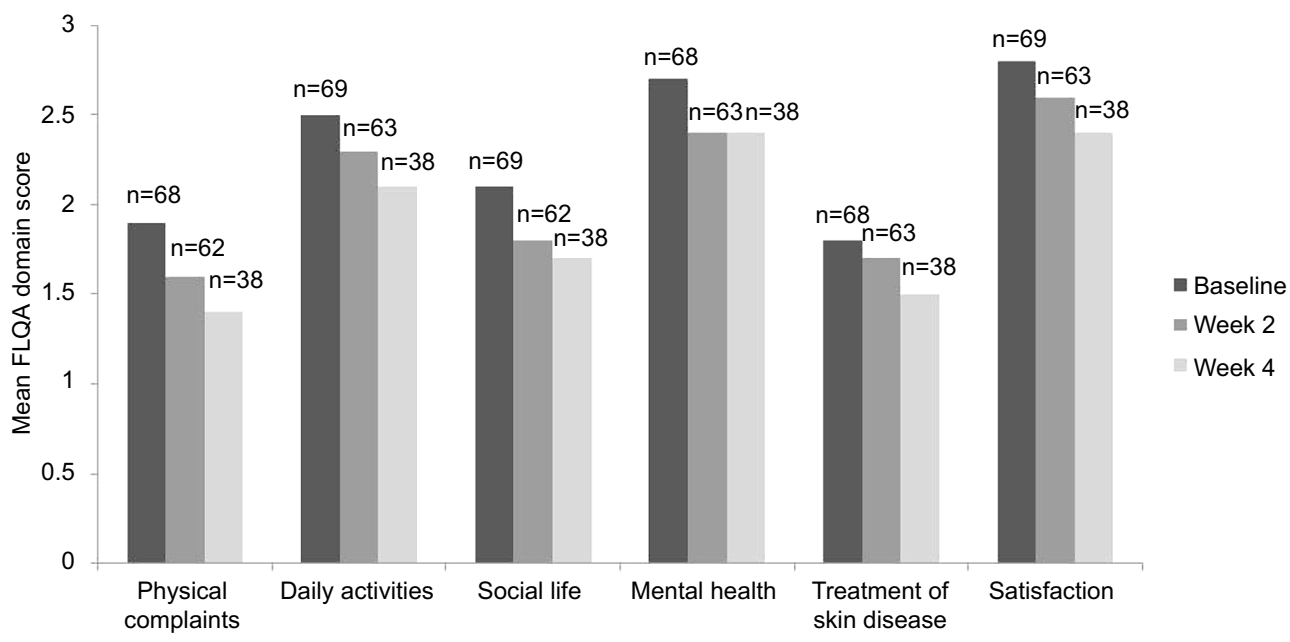

Figure SI Quality of life assessed using Freiburg Life Quality Assessment (FLQA) domain scores (all patients with available data).

Notes: Week 2 was end of study treatment for patients with atopic dermatitis and impetigo contagiosa; patients with acne vulgaris and rosacea were scheduled to receive 4 weeks of study treatment.

\section{Publish your work in this journal}

Clinical, Cosmetic and Investigational Dermatology is an international, peer-reviewed, open access, online journal that focuses on the latest clinical and experimental research in all aspects of skin disease and cosmetic interventions. This journal is included on PubMed. The manuscript management system is completely online and includes a very quick and fair peer-review system, which is all easy to use. Visit http://www.dovepress.com/testimonials.php to read real quotes from published authors 